\title{
Delay in diagnosis of patients with head-and-neck cancer in Canada: impact of patient and provider delay
}

\author{
S. Kassirian $\mathrm{MD}_{1}^{*}$ A. Dzioba $\mathrm{PhD}_{1}^{+}$S. Hamel $\mathrm{MD}_{1}^{+}$K. Patel $\mathrm{MD}_{1}^{\neq}$A. Sahovaler $\mathrm{MD}_{,}^{\dagger}$ \\ D.A. Palma MD MSc PhD, ${ }^{\S}$ N. Read MD, ${ }^{\S}$ V. Venkatesan DLO, ${ }^{\S}$ A.C. Nichols $\mathrm{MD}^{+}$ \\ J. Yoo MD, ${ }^{\dagger}$ K. Fung $\mathrm{MD}_{1}^{+}$A. Mendez $\mathrm{MD}^{+}$and S.D. MacNeil MD MSc${ }^{\dagger}$
}

\begin{abstract}
Background Head-and-neck cancers (HNCs) often present at an advanced stage, leading to poor outcomes. Late presentation might be attributable to patient delays (reluctance to seek treatment, for instance) or provider delays (misdiagnosis, prolonged wait time for consultation, for example). The objective of the present study was to examine the length and cause of such delays in a Canadian universal health care setting.
\end{abstract}

Methods Patients presenting for the first time to the HNC multidisciplinary team (MDT) with a biopsy-proven HNC were recruited to this study. Patients completed a survey querying initial symptom presentation, their previous medical appointments, and length of time between appointments. Clinical and demographic data were collected for all patients.

Results The average time for patients to have their first appointment at the MDT clinic was 15.1 months, consisting of 3.9 months for patients to see a health care provider (HCP) for the first time since symptom onset and 10.7 months from first HCP appointment to the MDT clinic. Patients saw an average of 3 HCPs before the MDT clinic visit (range: 1-7). No significant differences in time to presentation were found based on stage at presentation or anatomic site.

Conclusions At our tertiary care cancer centre, a patient's clinical pathway to being seen at the MDT clinic shows significant delays, particularly in the time from the first HCP visit to MDT referral. Possible methods to mitigate delay include education about HNC for patients and providers alike, and a more streamlined referral system.

Key Words Delay in presentation, head-and-neck cancer, patient-reported outcomes

Curr Oncol. 2020 October27(5)e467-e477

www.current-oncology.com

\section{INTRODUCTION}

In 2019, head-and-neck cancers (HNCs) had a projected incidence of approximately 6500 new cases in Canada, with approximately 1800 related deaths ${ }^{1}$. The modality of treatment is site- and stage-dependent, but HNC is managed largely with surgery or radiation, or both ${ }^{2}$. Tumour stage at presentation is one of the most significant prognostic factors for HNC outcome ${ }^{3}$. Delays in treatment initiation have been well-documented to result in advanced clinical presentation $^{4-8}$. However, the impact of delay in diagnosis on survival and quality-of-life outcomes is less well known $n^{9,10}$. Presumably, patients who experience a delay in diagnosis present with more advanced-stage cancer and experience poor outcomes; however, such a link has not been established.

In Ontario, a substantial effort has been made to reduce wait times for patients with HNC once a referral is made to a head-and-neck oncologist. Referrals are received from a variety of sources, including general otolaryngologists, dentists, oral surgeons, and general practitioners. Wait times to consultation and then from initial consultation to treatment are tracked, and efforts are ongoing at all major head-and-neck institutions to reduce wait times. As of January 2020 in Ontario, $89 \%$ of patients are seen for a first HNC surgical appointment within the target time, and $70 \%$ 
of patients are treated within the target time from decision to cancer surgery ${ }^{11}$. Similar data have been reported for HNC radiation wait times ${ }^{12}$. Although the quality improvement process has been a success, studies suggest that a much more significant delay occurs before the initial consultation with a head-and-neck oncologist, with many patients reporting multiple referrals, misdiagnoses, prolonged wait times for biopsies and imaging, and lack of awareness on the part of both the provider and the patient about the signs and symptoms of $\mathrm{HNC}^{13,14}$.

The delay before assessment by a head-and-neck oncologist can be divided into two main phases: patient delay and provider delay. Patient delay results when individuals do not immediately seek medical attention for a new symptom and is defined as the time from first symptom to first visit with a health care provider (HCP). Provider delay occurs once the patient has made initial contact with the first HCP for a symptom and is defined here as the time from the visit with the HCP by the patient to the time of presentation at the multidisciplinary team (MDT) clinic. The total length of patient and provider delay has been poorly studied to date, and the causes for the component delays are largely unknown.

In the present study, we sought to determine, for a prospective cohort of consecutive new patients with HNC, the lengths and causes of delay until presentation to the head-and-neck oncologist (MDT clinic) at our high-volume HNC centre. We hypothesized that a significant proportion of the delay in presentation to the head-and-neck MDT clinic would result from provider delay and multiple HCP referrals.

\section{METHODS}

\section{Inclusion Criteria}

All new adult patients with HNC presenting to the headand-neck cancer MDT clinic at the London Regional Cancer Program from September 2017 to September 2018 were eligible for inclusion. The London Regional Cancer Program, which services Southwestern Ontario, sees approximately 400 new patients with HNC per year. All patients presenting to the head-and-neck MDT clinic must have a biopsy-proven diagnosis of cancer. With few exceptions, once a referral is made to the head-and-neck MDT, patients are seen within 2 weeks in the clinic, with most being seen in less than 1 week. Patients are assessed by a head-and-neck surgical oncologist, a head-and-neck radiation oncologist, and other members of the MDT. We recruited all new adult patients who were able to read and write in English, excluding patients with recurrent cancer and patients with non-HNCs.

\section{Survey Development}

A survey was developed based on a previously validated Cancer Symptom Interval Measure questionnaire targeted for patients with malignancy (Table I ${ }^{15}$. The questionnaire queried patients about presenting symptoms, the timing of initial symptoms or signs, the time of first visit with a HCP, and the number of health care visits before referral to the head-and-neck MDT clinic. Patient demographics-including age, sex, history of smoking, alcohol use, education, employment, and place of residence-were also requested. The survey was distributed in hard copy. The Research Ethics Board at Western University approved the study (no. 109197). All patients who participated in the study signed a written consent form.

\section{Data Collection}

All new consecutive patients with HNC who presented to the head-and-neck MDT were invited to participate in the study. Patients were approached at the time of their initial consultation at the clinic. A diagnosis of cancer had been delivered, but in some cases, patients were not aware of the treatment that they would receive. The study coordinator obtained consent and administered the study questionnaire. Although the survey was self-administered, given the distress that patients were experiencing and the difficulty that some patients had in remembering timelines, the study coordinator was present with the patients while they completed the questionnaire to assist with question comprehension and to encourage patients to do their best with memory recollection. Additional information about the exact cancer type, site, and staging was collected from patient charts. The TNM tumour staging followed the 7th edition of the American Joint Committee on Cancer staging manual ${ }^{16}$.

\section{Study Outcomes}

The two primary study outcomes were these points of possible delay: time from the patient first noticing symptoms to first presentation to a HCP (patient-related delay) and time from first presentation to a HCP to first presentation to the MDT clinic (provider-related delay). Those intervals were further segmented into time between making an appointment with a HCP and being seen, seeing a HCP to imaging, and seeing a HCP to biopsy. We also recorded the number of HCPs that a patient saw before being referred to the MDT clinic.

Subgroup analyses were performed to determine whether there were associations of clinical and patient characteristics (stage of disease, HNC site, history of smoking, history of alcohol use, living situation, age, sex, and education) with the study outcomes already described.

\section{Data Analysis}

Study outcomes were descriptively analyzed. Frequency statistics and means with standard deviations were calculated for patient demographics, clinical presentation, and time intervals in the diagnostic pathway (that is, from onset of symptoms, to time taken to make an appointment, to diagnosis). A Pearson chi-square or Fisher exact test (where appropriate) was conducted to compare differences in rates of presenting symptoms, demographic and clinical features, and patient-perceived delays in care and seeking medical attention. The independent samples $t$-test or analysis of variance (where appropriate) was conducted to compare mean differences for each subgroup on continuous study outcomes, including demographics, number of HCPs seen, and intervals in the care pathway. Data were analyzed using the IBM SPSS Statistics software application (version 25.0: IBM, Armonk, NY, U.S.A.). Statistical significance was determined $a$ priori at the alpha level of 0.05 . 
TABLE I London Health Sciences Centre multidisciplinary team patient survey for referral timings

Date ___ Study ID number

\section{Section 1}

1) What is the reason for today's appointment?

\section{Section 2}

1) Please check ALL symptoms, those that were present when you first became aware of this health problem:
$\square$ Mouth sore
$\square$ Trouble opening mouth
$\square$ Stuffy nose
$\square \quad$ Lump in the neck
$\square \quad$ Trouble chewing
$\square \quad$ Decreased sense of smell
$\square$ White patch
$\square$ Trouble swallowing
$\square \quad$ Trouble hearing
$\square \quad$ Red patch
$\square \quad$ Pain with swallowing
$\square \quad$ Draining ear
$\square$ Pain
$\square$ Change in voice
$\square \quad$ Double vision
$\square \quad$ Bleeding
$\square \quad$ Trouble breathing
$\square$ Watery eyes
$\square$ Loose teeth
$\square$ Headaches
$\square \quad$ Numbness or tingling
$\square$ Dentures that no longer fit
$\square$ Runny nose
$\square \quad$ New skin growth

$\square$ Other
A. Do you have a family doctor? $\square$ Yes $\square \quad$ No
B. When did your symptoms first occur? _____________ (Estimate the date)
C. When did you first tell a health care provider? 1 (Estimate the date)
D. Who did you first discuss your symptoms with?
$\square$ Family doctor
$\square$ Dentist
$\square$ Emergency
$\square \quad$ Walk-in clinic
$\square$ Oral surgeon
$\square \quad$ Nurse

$\square \quad$ Other

E. How long did it take you to see that health care provider? (Estimate the date)

F. Did this health care provider examine the area of concern? $\square$ Yes $\square$ No

2) Do you think there was a delay in your care? $\square \quad$ Yes $\square \quad$ No

3) Did you wait in seeking medical attention for your symptoms? $\square$ Yes $\square$ No

\section{Section 3}

This section will provide us with the referral process and patient pathway in diagnosis of their head and neck cancer.

Please list the specialties and the dates seen for all health care providers you have seen for the problem listed above. Health care providers include ENT, oral surgeons, dentists, family doctors, emergency physicians, naturopaths, nurses, chiropractors, etc.

\section{Health Care Provider 1}

Specialty Month/year 1st seen Number of times seen

\section{Health Care Provider 2}

Specialty Month/year 1st seen 1 Number of times seen

Health Care Provider 3

Specialty Month/year 1st seen Number of times seen

\section{Health Care Provider 4} Specialty Month/year 1st seen Number of times seen

\section{Health Care Provider 5}

Specialty Month/year 1st seen

Number of times seen 
TABLE I Continued

Section 4

This section will ask you some questions about smoking, alcohol intake, your employment status.

1) Are you/have you ever been a smoker? $\square$ Yes $\square \quad$ No

A. How much do you smoke per day? Please specify packs or cigarettes. /day

B. How many years have you smoked for? years

C. If you quit, how many years ago did you quit? years

2) How many alcoholic drinks do you have per day? Please specify what the drink is:

3) Which best describes your employment status? (Please tick one box only)
$\square \quad$ Employed full-time
$\square \quad$ Unemployed (not seeking work)
Permanent sick/disabled
$\square \quad$ Employed part-time
$\square$ Retired
$\square \quad$ Unemployed (seeking work)
$\square$ Student
Temporarily sick/disabled

$\square \quad$ Other

4) What is your highest education level? (Please tick one box only)
$\square \quad$ Degree (or equivalent)
High school
$\square$ Diploma (or equivalent)
$\square$ Did not complete high school

Section 5

This questionnaire helps your physician to know how you are feeling. Read every sentence, place an " $X$ " on the answer that best describes how you have been feeling during the LAST WEEK. You do not have to think too much to answer. In this questionnaire, spontaneous answers are more important.

\author{
A I feel tense or 'wound up' \\ Most of the time \\ A lot of the time \\ From time to time (occasionally) \\ Not at all \\ D I still enjoy the things I used to enjoy \\ Definitely as much \\ Not quite as much \\ Only a little \\ Hardly at all
} about to happen

Very definitely and quite badly

Yes, but not too badly

A little, but it doesn't worry me

Not at all

D I can laugh and see the funny side of things

As much as I always could

Not quite so much now

Definitely not so much now

Not at all

A Worrying thoughts go through my mind

A great deal of the time

A lot of the time

From time to time, but not often

Only occasionally

\section{I feel cheerful}

Not at all

Not often

Sometimes

Most of the time

\section{I feel as if I am slowed down}

Nearly all the time 3

Very often 2

Sometimes 1

Not at all 0

A I get a sort of frightened feeling like "butterflies" in the stomach Not at all

Occasionally

Quite often

Very often

D I have lost interest in my appearance

Definitely

don't take as much care as I should 2

I may not take quite as much care 1

I take just as much care

A I feel restless as I have to be on the move

Very much indeed

Quite a lot

Not very much

Not at all

D I look forward with enjoyment to things

As much as I ever did

Rather less than I used to

Definitely less than I used to

Hardly at all

A I get sudden feelings of panic

Very often indeed

Quite often

Not very often

Not at all 
TABLE I Continued

\begin{tabular}{llll}
\hline A I can sit at ease and feel relaxed & & D I can enjoy a good book or radio/TV program \\
Definitely & 0 & Often & 0 \\
Usually & 1 & Sometimes & 1 \\
Not often & 2 & Not often & 2 \\
Not at all & 3 & Very seldom & 3
\end{tabular}

Section 6 (health care provider use only)

Type and location of patient's cancer

TNM staging of patient's cancer T N M Date of staging

Some people experience pain or discomfort for different reasons

Do you have any pain or discomfort? If yes, please explain

Do you think your pain is controlled?

If yes, please answer the following

What does it feel like?

What makes your pain worse?

What makes your pain better?

Please check if you live o alone $\square$ with spouse $\square$ with family $\square$ other

Do you have any children? $\square$ Yes $\square$ No If yes, do they live at home?

What is your occupation?

Are you worried about the impact the illness has had or may have on your financial resources?

\section{Onset of symptoms}

Date (estimate)

Specialty:

$\square$ Family doctor

$\square$ Dentist

$\square$ Oral surgeon

$\square$ Emergency

$\square$ Nurse

$\square$ Other Investigations:

$\square$ Ultrasound
$\square$ CT scan
$\square \mathrm{MRI}$
$\square$ Biopsy

\section{1st Health Care Visit}

Date (estimate) Specialty:

$\square$ Family docto

$\square$ Dentist

$\square$ Oral surgeon

$\square$ Emergency

$\square$ Nurse

$\square$ Other Investigations:
$\square$ Ultrasound
$\square$ CT scan
$\square \mathrm{MRI}$
$\square$ Biopsy

\section{2nd Health care visit}

Date (estimate)

Specialty:

$\square$ Family doctor

$\square$ Dentist

$\square$ Oral surgeon

$\square$ Emergency

$\square$ Nurse

$\square$ Other Investigations:

$\square$ Ultrasound

$\square$ CT scan

$\square \mathrm{MRI}$

$\square$ Biopsy

3rd Health Care Visit

Date (estimate)

Specialty:

\begin{tabular}{|c|c|c|c|c|c|}
\hline$\square$ Family doctor & $\square$ Dentist & $\square$ Oral surgeon & $\square$ Emergency & $\square$ Nurse & $\square$ Other \\
\hline Investigations: & П СТ scan & П МRI & & & \\
\hline
\end{tabular}


TABLE I Continued

Section 6 (health care provider use only)

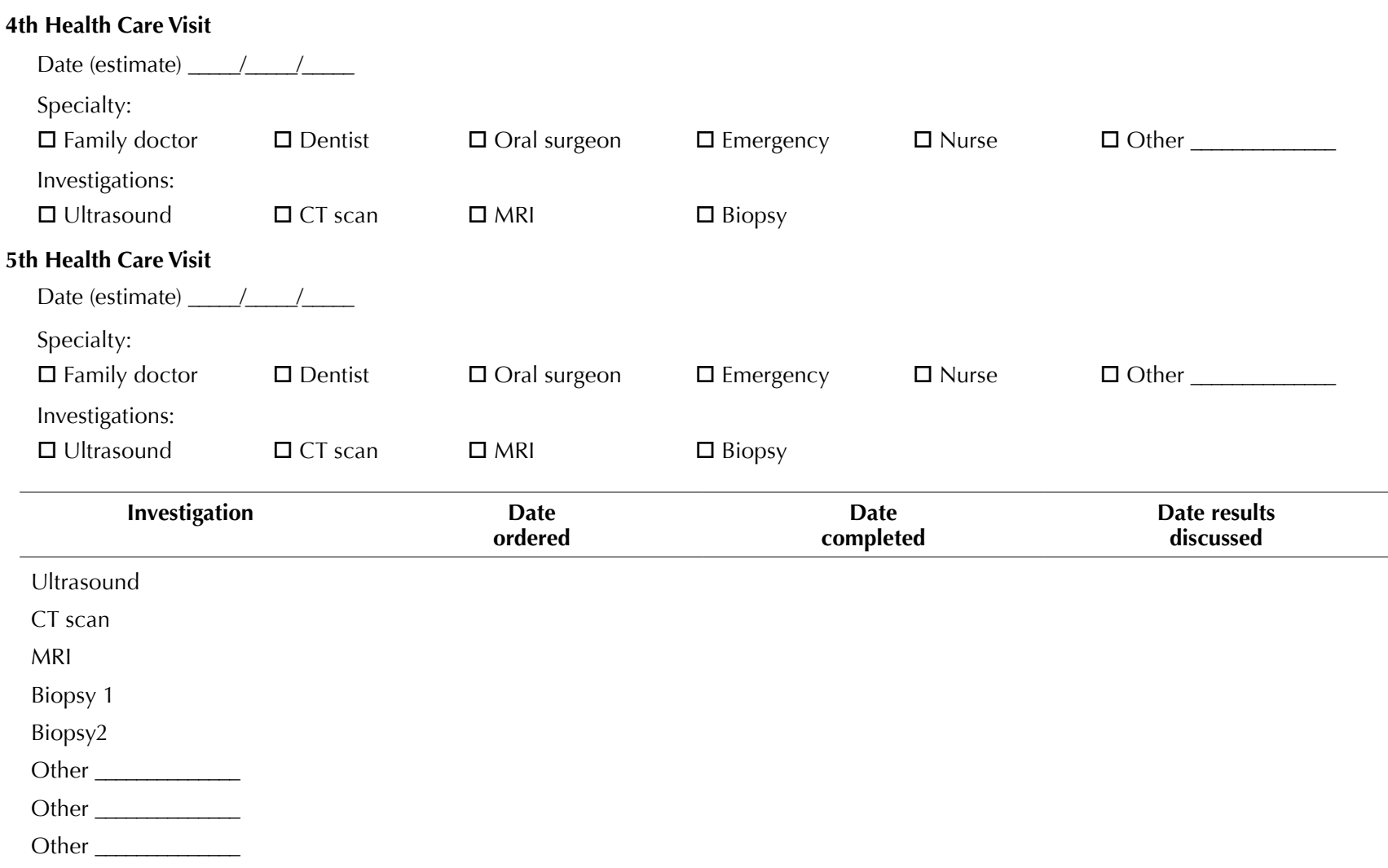

$\mathrm{ENT}=$ ear, nose, throat; $\mathrm{CT}=$ computed tomography; $\mathrm{MRI}=$ magnetic resonance imaging.

\section{RESULTS}

\section{Baseline Characteristics}

Tables II and III summarize patient demographics and characteristics of the malignancy. Mean age of the patients was 67.5 years, and most patients were men $(78.4 \%)$. The most common site was the oral cavity, with squamous cell carcinoma constituting $78.4 \%$ of the histology. There was an even distribution of patients presenting with early- and advanced-stage disease. In terms of smoking history, 64 patients $(62.7 \%)$ had a history of smoking. The only baseline characteristic that was significantly different between the early-stage and advanced-stage groups was number of years smoked: compared with individuals in the advanced-stage group, individuals in the early-stage group had smoked for a fewer number of years (mean: 25.6 years vs. 34.2 years; $p=0.04$ ). No baseline characteristics differed significantly between the early-stage and advanced-stage groups.

\section{Initial Presenting Symptoms}

The most common presenting symptom in all patients was a lump in the neck (38.2\%); other symptoms were pain in the primary malignancy site $(24.5 \%)$, a mouth sore $(20.6 \%)$, change in voice $(16.7 \%)$, and a new skin growth $(14.7 \%)$. Compared with the early-stage group, the advanced-stage group had a higher rate of having a lump in the neck as their presenting symptom ( $43.1 \%$ vs. $27.9 \%, p=0.05)$. Otherwise, there were no significant differences in initial symptoms between the early- and advanced-stage groups.

\section{Intervals in the Care Pathway}

Table IV summarizes the intervals between events in the diagnostic pathway from symptom onset to first visit to the MDT clinic. Mean time from symptom onset to presentation to a HCP was 3.9 months-effectively, the patientdelay interval. It took an average of 0.2 months (7.1 days) to obtain an appointment with a HCP once contact had been made by the patient. The time from presentation to first HCP to the MDT appointment was 10.7 months-effectively, the provider-delay interval. The mean time from first HCP visit to biopsy was 9.8 months. The total time from first onset of symptoms to presentation at the MDT clinic was 15.1 months. No correlation of any of those time intervals with age, sex, education status, living situation, having children, having a family doctor, history of smoking, history of alcohol use, tumour site, or presentation with early- or advanced-stage disease was observed ( $p>0.05$, Table IV).

\section{HCPs Seen Before the MDT Clinic Appointment}

The mean number of HCPs seen before the appointment at the MDT clinic was 3 (range: 1-7). More than 3 HCPs had been seen by $51 \%$ of patients with early-stage disease and by $59.5 \%$ of patients with advanced-stage disease. No significant differences were noted in the mean number of HCPs 
TABLE II Patient demographics

\begin{tabular}{|c|c|c|c|c|}
\hline \multirow[t]{2}{*}{ Characteristic } & \multicolumn{3}{|c|}{ Disease stage } & \multirow{2}{*}{$\underset{\text { Value }^{a}}{p}$} \\
\hline & Early & Advanced & Overall & \\
\hline Patients (n) & 43 & 51 & $102^{b}$ & \\
\hline Mean age (years) & $68.65 \pm 12.04$ & $68.27 \pm 11.13$ & $67.51 \pm 11.98$ & 0.88 \\
\hline $\operatorname{Sex}[n(\%)$ men $]$ & $33(76.7)$ & $41(80.4)$ & $80(78.4)$ & 0.67 \\
\hline Employment [n (\%) retired] & $26(60.5)$ & $33(64.7)$ & $62(60.8)$ & 0.67 \\
\hline Education $[n(\%) \geq$ high school] & $34(79.1)$ & $36(70.6)$ & $77(75.3)$ & 0.35 \\
\hline Living situation [n (\%) alone] & $11(25.5)$ & $10(19.6)$ & $22(21.6)$ & 0.49 \\
\hline Have children $[n(\%)]$ & $31(72.1)$ & $40(78.4)$ & $76(74.5)$ & 0.48 \\
\hline Have a family doctor $[n(\%)]$ & $43(100)$ & $46(90.2)$ & $96(94.1)$ & 0.11 \\
\hline \multicolumn{5}{|l|}{ Smoking status } \\
\hline History of smoking [n (\%)] & $26(60.5)$ & $33(64.7)$ & $64(62.7)$ & 0.53 \\
\hline Currently smoking [n (\%)] & $7(16.3)$ & $13(25.5)$ & $23(22.5)$ & 0.55 \\
\hline Mean years smoked & $25.60 \pm 16.43$ & $34.19 \pm 12.22$ & $29.97 \pm 14.43$ & 0.04 \\
\hline Mean cigarettes daily & $19.90 \pm 14.12$ & $18.23 \pm 11.70$ & $18.41 \pm 12.53$ & 0.63 \\
\hline Mean pack-years & $30.35 \pm 30.90$ & $31.41 \pm 21.17$ & $29.73 \pm 25.23$ & 0.88 \\
\hline \multicolumn{5}{|l|}{ Alcohol status } \\
\hline Current user [n (\%)] & $29(67.4)$ & $37(72.5)$ & $71(69.6)$ & 0.72 \\
\hline Previous abuse [n (\%)] & $2(4.7)$ & $2(3.9)$ & $4(3.9)$ & 0.86 \\
\hline Mean drinks daily & $1.92 \pm 1.60$ & $2.38 \pm 2.08$ & $2.10 \pm 1.85$ & 0.42 \\
\hline
\end{tabular}

seen before the MDT clinic visit, including by cancer stage group $(p>0.05)$.

\section{Patient Perception of Delay}

Of the surveyed patients, $29 \%$ discussed their symptoms at a routine visit with their primary HCP. A statistically significantly higher proportion of patients in the early-stage group $(41.9 \%)$ than in the advanced-stage group $(15.7 \%)$ spoke to their primary HCP about their symptoms during a routine visit $(p=0.01)$. After their symptoms started, $51 \%$ of patients delayed seeking medical care. A statistically significant higher proportion of patients in the early-stage group $(67.4 \%)$ than in the advanced-stage group $(41.2 \%)$ waited to seek medical attention for their symptoms $(p=0.01)$. A perception of a delay in their care was expressed by $55 \%$ of patients, with no difference between the early- and advanced-stage groups ( $p>0.05)$, and $52 \%$ of patients expressed regret and wished that they had done things differently to speed up their care, with no difference between the early- and advanced-stage groups $(p>0.05)$.

No differences in perceived delay were associated with education level, employment status, children, smoking or alcohol use, or early- and advanced-stage disease $(p>0.05)$. However, a significant difference with respect to waiting to seek medical attention was noted between patients who lived alone and those who did not $(68.2 \%$ vs. $42.9 \%$ respectively, $p=0.04$ ).

\section{DISCUSSION}

In this study, we report that the total delay in diagnosis from first symptom onset to presentation at our head-and-neck
MDT clinic was 15.07 months. The greatest delay was provider-caused delay (from first HCP encounter to presentation at the MDT clinic). On average, $50 \%$ of patients had to see 3 HCPs before presenting to the MDT clinic. We addressed total delay in diagnosis for all HNC sites and considered a wide variety of relevant patient- and tumour-related factors, finding no correlation of any patient or tumour factor with delay in presentation.

The mean patient-caused delay in our study from first symptom onset to presentation to a HCP was almost 4 months. Previous studies have demonstrated a similar mean patient delay: $3.7-4.3$ months for all $\mathrm{HNCs}^{13,17}$ and 3.5-5.4 months for oral cancers ${ }^{18}$. Several studies found that certain patient factors were associated with the interval before first presentation to a HCP: fear, lack of pain, lack of suspicion of cancer, smoking history, and socioeconomic factors $17,19,20$. We did not find that tumour site, socioeconomic factors, or smoking history correlated with patient delay. In the literature, findings are variable, with some studies demonstrating a correlation between cancer site and patient delay ${ }^{17,21,22}$ and other studies, not ${ }^{20,22-24}$.

We did not find that stage at presentation was associated with patient delay. The association between patient delay and stage at presentation has previously been studied with varying results $7,20,22,23$. Given that our study included patients with HNC at all sites, the presenting symptoms and intensity of symptoms could have been quite variable, which might account for the lack of an association. Given that $19.6 \%$ of patients in our study had an oropharynx cancer, which, when related to infection with the human papillomavirus, often presents with an asymptomatic neck mass ${ }^{25}$, the lack of correlation for site and stage of 
TABLE III Cancer characteristics

\begin{tabular}{|c|c|c|c|}
\hline \multirow[t]{2}{*}{ Characteristic } & \multicolumn{3}{|c|}{ Stage $[n(\%)]$} \\
\hline & Early & Advanced & Overall \\
\hline Patients & 43 & 51 & $102^{\mathrm{a}}$ \\
\hline $\begin{array}{l}\text { Histology } \\
\text { Squamous cell carcinoma } \\
\text { Other }\end{array}$ & $\begin{array}{c}34(79.1) \\
9(20.9)\end{array}$ & $\begin{array}{l}41(80.4) \\
10(19.6)\end{array}$ & $\begin{array}{l}80(78.4) \\
22(21.6)\end{array}$ \\
\hline $\begin{array}{l}\text { Site } \\
\text { Oral cavity } \\
\text { Oropharynx } \\
\text { Salivary glands } \\
\text { Larynx } \\
\text { Hypopharynx } \\
\text { Nasal cavity or } \\
\quad \text { paranasal sinuses } \\
\text { Other }\end{array}$ & $\begin{array}{c}17(39.5) \\
5(11.6) \\
7(16.3) \\
5(11.6) \\
0(0) \\
1(2.3) \\
8(18.6)\end{array}$ & $\begin{array}{c}12(23.5) \\
14(27.5) \\
3(5.9) \\
6(11.8) \\
4(7.8) \\
1(2.0) \\
9(17.7)\end{array}$ & $\begin{array}{c}31(30.4) \\
20(19.6) \\
13(12.7) \\
11(10.8) \\
4(3.9) \\
2(2) \\
21(20.1)\end{array}$ \\
\hline $\begin{array}{l}\text { AJCC stage } \\
\text { I } \\
\text { II } \\
\text { III } \\
\text { IV } \\
\text { Unknown }\end{array}$ & $\begin{array}{c}21(48.8) \\
22(51.2) \\
0(0) \\
0(0) \\
0(0)\end{array}$ & $\begin{array}{c}0(0) \\
0(0) \\
18(35.3) \\
33(64.7) \\
0(0)\end{array}$ & $\begin{array}{c}21(20.6) \\
22(21.6) \\
18(17.6) \\
33(32.4) \\
8(7.8)\end{array}$ \\
\hline $\begin{array}{l}\text { T Stage } \\
\text { T1 } \\
\text { T2 } \\
\text { T3 } \\
\text { T4 } \\
\text { Tx }\end{array}$ & $\begin{array}{c}20(46.5) \\
21(48.8) \\
2(4.7) \\
0(0) \\
0(0)\end{array}$ & $\begin{array}{c}7(13.7) \\
14(27.5) \\
10(19.6) \\
20(39.2) \\
0(0)\end{array}$ & $\begin{array}{c}27(26.5) \\
35(34.3) \\
12(11.8) \\
20(19.6) \\
8(7.8)\end{array}$ \\
\hline $\begin{array}{l}\text { N Stage } \\
\text { N0 } \\
\text { N1 } \\
\text { N2 } \\
\text { N3 } \\
\text { Nx }\end{array}$ & $\begin{array}{c}37(86.0) \\
3(7) \\
1(2.3) \\
0(0) \\
2(4.7)\end{array}$ & $\begin{array}{c}10(19.6) \\
12(23.5) \\
24(47.1) \\
3(5.9) \\
2(3.9)\end{array}$ & $\begin{array}{c}47(46.1) \\
15(14.7) \\
28(27.5) \\
3(2.9) \\
9(8.8)\end{array}$ \\
\hline $\begin{array}{l}\text { M Stage } \\
\text { M0 } \\
\text { M1 } \\
\text { Mx }\end{array}$ & $\begin{array}{c}36(83.7) \\
0(0) \\
7(16.3)\end{array}$ & $\begin{array}{c}41(80.4) \\
2(3.9) \\
8(15.7)\end{array}$ & $\begin{array}{c}77(75.5) \\
2(2) \\
23(22.5)\end{array}$ \\
\hline
\end{tabular}

a Of 102 total patients, 8 had disease of unknown stage based on American Joint Committee on Cancer criteria. Of 80 patients with squamous cell carcinoma and 22 with "other" histology, 5 and 3 respectively had disease of unknown stage.

presentation with patient delay might have been influenced by that subgroup. A larger sample size would have allowed for subgroup analyses by site of HNC.

The most common presenting symptom for HNC in our cohort was a neck mass, followed by pain at the primary cancer site and a mouth sore. Other studies have found that the presence of a neck mass or lymphatic metastasis has resulted in a shorter patient delay ${ }^{17,20,23}$. Pain was the second most common presenting symptom in our study. Two studies found that pain has no effect on patient delay ${ }^{17,24}$, and one study found a shorter patient delay for patients experiencing pain ${ }^{20}$. In a mixed-methods study by Lee et al., reasons for patient delay reported by patients included a lack of awareness of the signs and symptoms of HNC (61\% of patients), believing that alternative medicines would cure their disease ( $20 \%$ of patients), and not knowing that smoking and alcohol could cause HNC (57\% of patients) ${ }^{13}$. Lack of awareness, education, and knowledge of the risk factors for HNC-plus the low profile of HNC in the public media-might all be factors contributing to patient delay and thus deserving of further study ${ }^{3,20}$.

We did not find that sociodemographic or socioeconomic factors correlated with mean patient delay; however, when patients were asked about their perception of delay, patients who lived alone were more likely to delay seeking medical attention. The finding of no correlation between sociodemographic or socioeconomic factors and patient delay is consistent with results in other studies ${ }^{17,21,23,24}$.

Smoking status and alcohol consumption also did not appear to affect patient delay. Previous studies in Finland, which has a national public health care system and allows patients to seek medical care regardless of income, have demonstrated that a lower socioeconomic status leads to longer patient delays ${ }^{26,27}$.

Our study highlighted regret on the part of more than half the patients that they did not seek attention sooner. Addressing patient delay is more complex than simply providing education about the risk factors for HNC, or awareness or screening campaigns. A review by Noonan ${ }^{26}$ about patient delay in oral cancer suggests that application of a psychosocial theoretical model to studies in the field of diagnostic delay should be used, because the perception of the signs of cancer by patients might be misunderstood and lead patients to erroneous behavioural responses that might delay them in seeking medical attention ${ }^{26}$.

The longest period of delay was found in the provider interval: almost 11 months from the first HCP visit to the first MDT clinic visit. It is worth noting that this particular delay interval is variably defined in the literature. Some publications describe physician delay as the interval from first HCP visit to date of diagnosis (biopsy date) ${ }^{19}$; others describe diagnostic delay as the time from referral by a HCP to the final treatment decision by a multidisciplinary tumour conference ${ }^{22}$. We chose to define provider delay as the time from first HCP presentation to presentation at the MDT clinic so as to ensure that the entire time from first contact with a HCP until the treatment decision was made in the MDT clinic was included.

In Ontario, regionalization of HNC care has resulted in all patients with HNC being treated at a small number of high-volume HNC centres. In the past, patients might have been treated by community head-and-neck surgeons or radiation oncologists working in smaller centres, but today's patients might first have to be seen by a community otolaryngologist or oral surgeon for diagnosis. They are then referred to the regional HNC treatment centre. We hypothesized that the new pathway might result in longer provider delays and multiple HCP referrals. We found that the provider delay was substantially longer than the delay that has been reported in the literature. The mean provider delay in our study was 11 months. A previous study conducted in Ontario in 2016 demonstrated a mean provider delay of 8.3 months-although the patients in that study were seen by a head-and-neck surgeon and not at a MDT clinic ${ }^{13}$. Other studies have demonstrated shorter provider delays 
TABLE IV Intervals for diagnostic pathway events from symptom onset to first multidisciplinary team (MDT) visit

\begin{tabular}{|c|c|c|c|c|c|}
\hline \multicolumn{2}{|c|}{ Event } & \multicolumn{3}{|c|}{ Mean interval (months), by stage } & \\
\hline From & To & Early & Advanced & Overall & \\
\hline First symptom onset & 1st HCP visit ${ }^{\mathrm{a}}$ & $5.51 \pm 16.09$ & $2.03 \pm 3.83$ & $3.93 \pm 11.71$ & 0.18 \\
\hline Appointment made & 1st HCP visit & $0.17 \pm 0.35$ & $0.31 \pm 0.61$ & $0.23 \pm 0.50$ & 0.18 \\
\hline First HCP visit & Imaging (US, CT, and MRI) & $9.39 \pm 20.60$ & $6.43 \pm 11.77$ & $8.12 \pm 16.19$ & 0.41 \\
\hline First HCP visit & Biopsy & $10.73 \pm 22.99$ & $8.21 \pm 13.79$ & $9.83 \pm 18.27$ & 0.60 \\
\hline First symptom onset & MDT visit & $16.23 \pm 27.73$ & $10.27 \pm 14.19$ & $15.07 \pm 31.54$ & 0.21 \\
\hline \multirow[t]{2}{*}{ First HCP visit } & MDT visit & $10.95 \pm 20.04$ & $8.04 \pm 12.59$ & $10.74 \pm 20.00$ & 0.39 \\
\hline & seen & & Patients [n (\%)] & & $p$ Value \\
\hline$<3$ & & 17 (40.5) & $25(49.0)$ & 45 (44.1) & 0.41 \\
\hline$\geq 3$ & & $25(59.5)$ & $26(51.0)$ & $56(54.9)$ & 0.41 \\
\hline
\end{tabular}

a Most common first HCP seen was a family doctor (69.6\% of total). Most common second, third, fourth, and fifth HCP seen was an otolaryngologist outside of the MDT clinic.

$\mathrm{HCP}=$ health care practitioner; $\mathrm{US}=$ ultrasonography; $\mathrm{CT}=$ computed tomography; $\mathrm{MRI}=$ magnetic resonance imaging.

outside of the Canadian health care system: approximately 3-5 months in the United Kingdom and 3 months in the United States ${ }^{3,6,7}$.

Although we did not examine whether provider delays have become longer since the regionalization of HNC care, regionalization might have contributed to a longer delay in our study than in others. We also found that patients saw a mean of 3 HCPs (range: 1-7) before being seen at the MDT clinic. Although the provider delay in our study did not affect stage at presentation, a mean delay of 11 months, with several referrals to HCPs, is undoubtedly prolonged and unacceptable. That length of delay could lead to increased patient anxiety and lack of trust in the health care system, with more than half the patients in our study experiencing regret and stating that they wished they had done things differently. Although treatment at high-volume head-andneck cancer centres has been shown to lead to improved outcomes for patients ${ }^{28,29}$, the effect that regionalization has had on diagnostic delay and patient care has not been thoroughly studied. We demonstrated that significant improvement could be made in provider delay in that regard.

Several components of the interval between first presentation to a HCP and the MDT clinic visit could have contributed to provider delay. Lack of a family doctor or poor access to a family doctor might have contributed, given that $30 \%$ of the patients in the present study presented to a HCP other than their family doctor. Provider education about the signs and symptoms of HNC might have contributed to provider delay, given that almost $40 \%$ of patients presented with a neck mass, which might have been interpreted by HCPs as having an infectious cause. Further, only $22 \%$ of patients were current smokers, which is a common risk factor for HNC and might have resulted in a lower suspicion of HNC by the HCP. The diagnostic workup and referral process might also have contributed to provider delay, including wait times for imaging, biopsy, and specialist referrals. A previous Canadian study identified lack of physician knowledge as a theme related to provider delay, identifying 3 subthemes, including inappropriate prescription of medications for infection or gastroesophageal reflux disease, lack of knowledge about the signs and symptoms of HNC, and inappropriate reassurance of good heath by $\mathrm{HCPs}^{13}$. Provider delay was longer than patient delay in our study, suggesting that the more effective intervention might be to focus first on shortening the total diagnostic delay. Possible ways to shorten provider delay include improving training for physicians and dentists about the signs and symptoms of HNC, providing continuing medical education about HNC, targeting dentists (who represented a significant proportion of the HCPs in our study), and streamlining the referral process so that patients avoid multiple referrals. Studies assessing educational programs or tools for physicians-in-training would be very useful.

The strengths of our study lie in the complete characterization of each patient's pathway to the MDT clinic. Previous studies have defined provider delay as the interval from first contact with a HCP to the date of diagnosis. However, in the health care system today, treatment decisions are not made until the patient is seen at the MDT clinic, and patients could experience further delay while waiting for imaging and referral to the MDT clinic. Other strengths include our description of the numbers and types of HCPs seen, the timing of patient appointments, and the perception of patients about their diagnostic care pathway. Furthermore, all those factors are viewed from the perspective of the Canadian health care system, eliminating some of the socioeconomic barriers that are a factor in other countries. Studies conducted in health care systems outside of Canada do not detail as many intervals in appointments and do not specify which HCPs were seen ${ }^{19,30,31}$. Furthermore, our study is prospective; other studies that have looked at similar data have been significantly affected by recall bias because of their retrospective design. Although recall bias remains an issue in the present study because of patient reporting, the prospective design reduces the effect. We tried to minimize recall bias by having patients complete the questionnaire during their first encounter at the MDT clinic. We also included all HNC sites and analyzed delay as a continuous variable. Certain studies have focused on the oral cavity alone and have therefore focused 
on the diagnostic sensitivity of HCPs with respect to lesions of the oral cavity ${ }^{4,31,32}$. However, many other symptoms, such as neck lumps, can be just as easily misdiagnosed or overlooked. Finally, we developed a survey based on a previously validated survey. We assisted patients in completing the survey, and we recruited consecutive patients.

Our study is limited in a number of ways. The first limitation is recall bias. Patients were asked to recall their awareness of their symptoms and their contact with HCPs, both of which can be influenced by inaccurate recall. We attempted to mitigate that limitation with a prospective design and a survey that was created to be as clear as possible, with precise instructions. However, we were not able to determine how accurate were the patient's responses about the delay experienced. The questionnaire was administered after the cancer diagnosis, during a stressful medical appointment in which patients were being informed of their treatment options. That environment might have affected the ability to accurately recall onset of symptoms, potentially leading to a falsely reconstructed sequence of events, given that the outcome was known to the patient. Further, the recall bias could have varied depending on the patient's symptoms, because some symptoms might have been more prominent than others. Patients-reported data concerning the duration of their symptoms are subjective and might have been underestimated, given that the patients were aware of the cancer diagnosis.

A second issue is the small sample size, which might have resulted in associations not being observed. In addition, only $22 \%$ of our sample were current smokers; the proportion of smokers in similar studies tends to be significantly higher, indicating that our sample might not be completely representative ${ }^{22,23}$.

Yet another limitation, particularly relevant to the Canadian health care system and cancer care in Ontario, is that we did not consider distance traveled and economic limitations. The number of designated HNC sites within the regional model in Ontario is small, which can lead to patients having to travel long distances for care.

\section{CONCLUSIONS}

We observed a significant duration of diagnostic delay, with the greatest delay being experienced as provider delay. Whether the observed lengthened intervals in the diagnostic timeline affect patient outcomes is still unclear. Certain measures could be taken to shorten the diagnostic delay, including educating HCPs and streamlining the referral process in the era of regionalization of HNC care. Future research should explore the efficacy of such interventions, and ultimately, whether those interventions result in improved outcomes.

\section{CONFLICT OF INTEREST DISCLOSURES}

We have read and understood Current Oncology's policy on disclosing conflicts of interest, and we declare that we have none.

\section{AUTHOR AFFILIATIONS}

*Department of Medicine and 'Department of Otolaryngology, Schulich School of Medicine and Dentistry, Western University, London Health Sciences Centre, London, ON; ${ }^{\ddagger}$ Department of Otolaryngology, Moffitt Cancer Center and Research Institute,
University of South Florida, Tampa, FL, U.S.A.; ${ }^{\S}$ Department of Radiation Oncology, Schulich School of Medicine and Dentistry, Western University, London Health Sciences Centre, London, ON.

\section{REFERENCES}

1. Canadian Cancer Statistics Advisory Committee. Canadian Cancer Statistics 2019. Toronto, ON: Canadian Cancer Society; 2019.

2. Wheless SA, McKinney KA, Zanation AM. A prospective study of the clinical impact of a multidisciplinary head and neck tumor board. Otolaryngol Head Neck Surg 2010;143:650-4.

3. Patel UA, Brennan TE. Disparities in head and neck cancer: assessing delay in treatment initiation. Laryngoscope 2012; 122:1756-60.

4. Chiou SJ, Lin W, Hsieh CJ. Assessment of duration until initial treatment and its determining factors among newly diagnosed oral cancer patients. Medicine (Baltimore) 2016; 95:e5632.

5. Mundi N, Theurer J, Warner A, et al. The impact of seasonal operating room closures on wait times for oral cancer surgery. Curr Oncol 2018;25:67-72.

6. McGurk M, Chan C, Jones J, O'Regan E, Sherriff M. Delay in diagnosis and its effect on outcome in head and neck cancer. Br J Oral Maxillofac Surg 2005;43:281-4.

7. Goy J, Hall SF, Feldman-Stewart D, Groome PA. Diagnostic delay and disease stage in head and neck cancer: a systematic review. Laryngoscope 2009;119:889-98.

8. Seoane J, Takkouche B, Varela-Centelles P, Tomás I, SeoaneRomero JM. Impact of delay in diagnosis on survival to head and neck carcinomas: a systematic review with meta-analysis. Clin Otolaryngol 2012;37:99-106.

9. Murphy CT, Galloway TJ, Handorf EA, et al. Survival impact of increasing time to treatment initiation for patients with head and neck cancer in the United States. J Clin Oncol 2016; 34:169-78.

10. Felippu AWD, Freire EC, de Arruda Silva R, Guimarães AV, Dedivitis RA. Impact of delay in the diagnosis and treatment of head and neck cancer. Braz JOtorhinolaryngol 2016;82:140-3.

11. Health Quality Ontario (HQO). Time from decision to having cancer surgery [Web resource]. Toronto, ON: HQO; 2020. [Available at: https://www.hqontario.ca/system-performance/waittimes-for-surgeries-and-procedures/wait-times-for-cancersurgeries/time-from-decision-to-having-cancer-surgery (select Head and Neck Cancers); cited 28 February 2020]

12. Ontario Health (Cancer Care Ontario) [OH(CCO)]. Radiation Treatment Program: Implementation Plan 2019-2023 [Web page]. Toronto, ON: $\mathrm{OH}(\mathrm{CCO}) ; 2018$. [Available at: https://www. cancercareontario.ca/en/cancer-care-ontario/programs/ clinical-services/radiation-treatment/implementation-plan \#: : text=Cancer\%20Care\%20Ontario's\%20target\%20 wait,80\%25\%20in\%202017\%2F2018; cited 21 September 2020]

13. Lee JJ, Dhepnorrarat C, Nyhof-Young J, Witterick I. Investigating patient and physician delays in the diagnosis of head and neck cancers: a Canadian perspective. J Cancer Educ 2016;31:8-14.

14. Yu T, Wood RE, Tenenbaum HC. Delays in diagnosis of head and neck cancers. J Can Dent Assoc 2008;74:61.

15. Neal RD, Nafees S, Pasterfield D, et al. Patient-reported measurement of time to diagnosis in cancer: development of the Cancer Symptom Interval Measure (C-SIM) and randomised controlled trial of method of delivery. BMC Health Serv Res 2014;14:3.

16. Edge SB, Byrd DR, Compton CC, Fritz AG, Greene FL, Trotti A, eds. AJCC Cancer Staging Manual. 7th ed. New York, NY: Springer-Verlag; 2009.

17. Nieminen M, Aro K, Jouhi L, Back L, Makitie A, Atula T. Causes for delay before specialist consultation in head and neck cancer. Acta Oncol 2018;57:1677-86. 
18. Stefanuto P, Doucet JC, Robertson C. Delays in treatment of oral cancer: a review of the current literature. Oral Surg Oral Med Oral Pathol Oral Radiol 2014;117:424-9.

19. Nash R, Hughes J, Sandison A, Stewart S, Clarke P, Mace A. Factors associated with delays in head and neck cancer treatment: case-control study. J Laryngol Otol 2015;129:383-5.

20. VäisänenJA, SyrjäläAMH, Pesonen PRO, Pukkila MJ, Koivunen PT, Alho OP. Characteristics and medical-care-seeking of head and neck cancer patients: a population-based crosssectional survey. Oral Oncol 2014;50:740-5.

21. Rogers SN, Pabla R, McSorley A, Lowe D, Brown JS, Vaughhan ED. An assessment of deprivation as a factor in the delays in presentation, diagnosis and treatment in patients with oral and oropharyngeal squamous cell carcinoma. Oral Oncol 2007;43:648-55.

22. Brouha XDR, Tromp DM, Koole R, Hordijk GJ, Winnubst JAM, de Leeuw JRJ. Professional delay in head and neck cancer patients: analysis of the diagnostic pathway. Oral Oncol 2007;43:551-6.

23. Koivunen P, Rantala N, Hyrynkangas K, Jokinen K, Alho OP. The impact of patient and professional diagnostic delays on survival in pharyngeal cancer. Cancer 2001;92:2885-91.

24. Amir Z, Kwan SY, Landes D, Feber T, Williams SA. Diagnostic delays in head and neck cancers. EurJCancer Care (Engl) 1999; 8:198-203.

25. Berman TA, Schiller JT. Human papillomavirus in cervical cancer and oropharyngeal cancer: one cause, two diseases. Cancer 2017;123:2219-29.
26. Noonan B. Understanding the reasons why patients delay seeking treatment for oral cancer symptoms from a primary health care professional: an integrative literature review. Eur J Oncol Nurs 2014;18:118-24.

27. Akram M, Siddiqui SA, Karimi AM. Patient related factors associated with delayed reporting in oral cavity and oropharyngeal cancer. Int J Prev Med 2014;5:915-19.

28. Gourin CG, Stewart CM, Frick KD, et al. Association of hospital volume with laryngectomy outcomes in patients with larynx cancer. JAMA Otolaryngol Head Neck Surg 2019;145: $62-70$.

29. Lin DJ, McConkey CC, Nankivell P, Dunn J, Mehanna H. The impact of institutional clinical trial recruitment versus hospital volume on survival outcomes of patients with head and neck cancer: an analysis of the PET-NECK trial outcomes, UKCRN portfolio, and Hospital Episode Statistics (HES) in England. Oral Oncol 2018;85:40-3.

30. Azhar N, Doss JG. Health-seeking behaviour and delayed presentation of oral cancer patients in a developing country: a qualitative study based on the self-regulatory model. Asian Pac J Cancer Prev 2018;19:2935-41.

31. Wang KH, Song BH, Gilde JE, et al. Diagnostic pathway of oral cavity cancer in an integrated health care system. Perm J 2018;22:17-152.

32. Liao CT, Chen HN, Wen YW, et al. Association between the diagnosis-to-treatment interval and overall survival in Taiwanese patients with oral cavity squamous cell carcinoma. Eur J Cancer 2017;72:226-34. 